\title{
Simulation and experiment study on cutting force of coated tool milling natural marble
}

\author{
Yan Guangyu*, Wu Yuhou**, Zhao Dehong***, Wang He**** \\ *Shenyang Jianzhu University, Shenyang 110168, China, E-mail:775083630@qq.com \\ **Shenyang Jianzhu University, Shenyang 110168, China, E-mail: wuyh@sjzu.edu.cn \\ ***Shenyang Jianzhu University, Shenyang 110168, China, E-mail: 85755340@qq.com \\ ****Shenyang Jianzhu University, Shenyang 110168, China, E-mail: $4404992 @ q q . c o m$ \\ cross $^{\text {ref }}$ http://dx.doi.org/10.5755/j01.mech.22.4.16160
}

\section{Introduction}

Natural marble is a typical brittle material that is easy to generate incontrollable brittle fracture in practical machining; it intensifies the tool wear and decreases processing efficiency [1]. The milling of natural marble is a complicated brittle deformation process and the whole process refers to thermodynamics, physics and so on. The flow stress characteristic of machining process is affected by a lot of factors. As a result, the research of natural marble requires a comprehensive research on the whole cutting process. With the rapid development of manufacturing industry, the traditional experimental method based on a large number of cutting experiment data can not satisfy the need in the field of difficult-to-machine materials [2]. Therefore, the primary work of studying characteristics of material cutting is designing a precise and reliable flow stress cutting mode. The modern highly developed computer technology ensures wide use of the finite element simulation software in the field of metal cutting. The finite element simulation has become a very effective method in the research of cutting characteristics and optimization process [3]. However, the simulation study on natural marble cutting characteristic has attracted little attention. There is few study on cutting force simulation in the present domestic stone processing field of our country. Yuan Juntang took the simulation of aluminum alloy cutting process by Deform-3D and study change rule of the milling force [4]. Cong Ming carried out the simulation research of drilling process of engine cylinder block through Deform-3D and optimized the cutting parameters.

Cutting force is a main reason of tool wear and workpiece brittle fracture during the high speed milling process of natural marble. Meanwhile, cutting force is an important composition of natural marble's cutting characteristics [5]; it is mainly affected by the machining parameters, which can be optimized by accurate prediction and thus help increase processing efficiency and save the processing cost. Natural marble milling process was simulated based on Deform-3D in this paper; the milling force data obtained by simulation and experiment were compared. The cutting parameters were optimized when coated tools milling natural marble and an effective analysis on mechanism of milling force was established.

\section{Establishment of milling finite element model}

\subsection{Establishment of material properties}

White marble is a kind of natural marble; it is mainly composed of calcium carbonate (CaCO3). The white marble has a close texture and high compressive strength. Secondary development of Deform Material Library was carried out based on basic material properties due to Deform-3D does not include the stone material whereas it includes stress, strain rate and temperature. This paper found out the elastic modulus, Poisson ratio, thermal conductivity and specific heat capacity of materials and coated tools. The basic attributes [6], [7] of workpiece and tool material are shown in Table 1.

Basic attributes of work piece and tool materials

\begin{tabular}{|c|c|c|c|c|c|c|}
\hline Material & $\begin{array}{c}\text { Density } \\
\rho, \mathrm{kg} \mathrm{m}^{-3}\end{array}$ & $\begin{array}{c}\text { Elasticity } \\
\text { modulus } E, \mathrm{GPa}\end{array}$ & $\begin{array}{c}\text { Poissn } \\
\text { ratio }\end{array}$ & $\begin{array}{c}\text { Thermal } \\
\text { expansivity, } 10^{-6}\end{array}$ & $\begin{array}{c}\text { Thermal } \\
\text { conductivity, } \mathrm{W} \mathrm{m}^{-1} \mathrm{~K}^{-1}\end{array}$ & $\begin{array}{c}\text { Specific heat capacity } \\
\mathrm{C}, \mathrm{J} \mathrm{kg}^{-1} \mathrm{~K}^{-1}\end{array}$ \\
\hline Natural marble & 2931 & 117.90 & 0.25 & 1.4 & 3.57 & 793 \\
\hline Ball endmill & 1487 & 448.00 & 0.23 & 8.0 & 30.00 & 502 \\
\hline
\end{tabular}

Natural marble milling process is a complicated brittle fracture process including little plastic cutting process. The flow stress is the nonlinear function of temperature, strain and strain rate. Equation (1) shows the stress and strain mechanical model in Deform Material Library which is commonly used material constitutive relation model. $\bar{\sigma}$ represents equivalent stress of work piece, $\bar{\varepsilon}$ represents equivalent strain, $\dot{\varepsilon}$ represents strain rate and $T$ represents temperature.

$$
\bar{\sigma}=\bar{\sigma}(\bar{\varepsilon}, \dot{\varepsilon}, T)
$$

where $\bar{\sigma}$ - equivalent stress of work piece, MPa; $\bar{\varepsilon}$ - equivalent strain; $\dot{\varepsilon}$ - strain rate; $T$ - temperature, ${ }^{\circ} \mathrm{C}$. The stress-strain curve7 (as shown in Fig. 1) of natural marble was drawn. According to the corresponding stress under different temperature and strain values filled in the material defined module in Deform. The ball endmill material is tungsten carbide (WC) and coating material is titanium carbonitride (TiCN) from tool material library of 
Deform. The parameters of two kinds of materials in the material property module are added and then finish the definition of material.

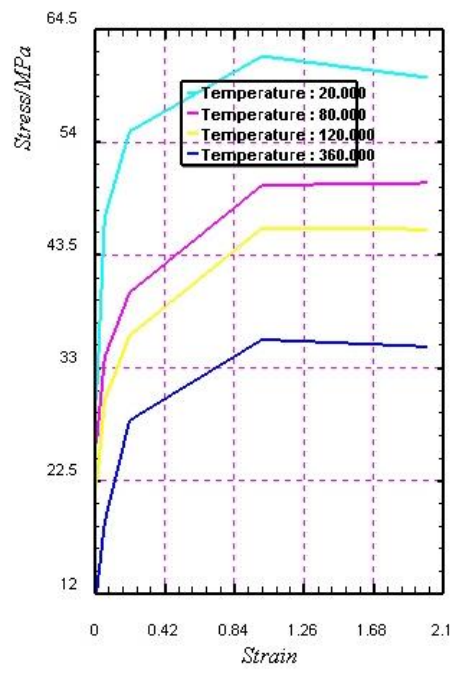

Fig. 1 Stress-strain curve of natural marble

\subsection{Establishment of milling model and meshing}

Milling force prediction has important significance on the research of natural marble milling characteris-

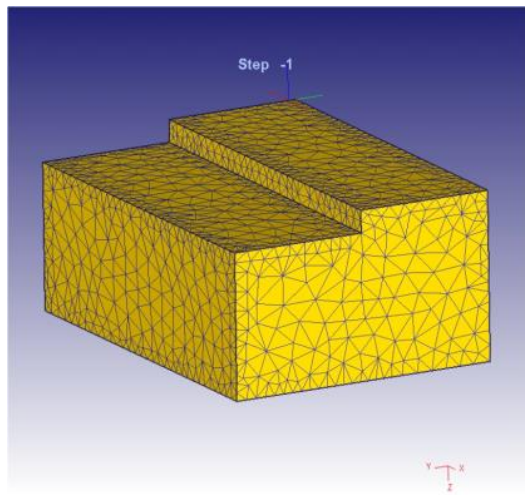

tics. The change characteristic of coated tool high speed under different cutting parameters was mainly studied in the simulation. The mechanism of the milling force was set up then. First, establishment of milling model and meshing of milling process [8] of coated tool should be carried on by Deform pretreatment module. $F x$ is the cutting force of feed direction, $F y$ is the cutting force of tangential direction, $F z$ is the cutting force of axial direction. The geometric parameter of cutting tools: helix angle $(\beta)$ is $45^{\circ}$, first clearance angle $\left(\alpha_{1}\right)$ is $10^{\circ}$, second clearance angle $\left(\alpha_{2}\right)$ is $15^{\circ}$, inclination angle $(\lambda)$ is $14^{\circ}$ and diameter $(d)$ is $6 \mathrm{~mm}$.

The four nodes tetrahedron element was used in the meshing of natural marble and coated tool in this paper. The four nodes element has the characteristics of simple collection features and it is one of the most basic elements in the finite element analysis. As Fig. 2 shows: the milling force curve of normal size of four nodes tetrahedron element is not accurate, it can not illustrate the relation between stress and stain precisely, the difference of value is big and it has few numerical points, so the element division of processing area needs a proper encryption [9] (as Fig. 3 shows). There are 45406 elements and 8042 polyhedrons in worpiece. The ratio of normal part and encryption part is 5:1. Fig. 3 shows the geometric model of ball endmill and natural marble created by Solidworks 3D modeling software.

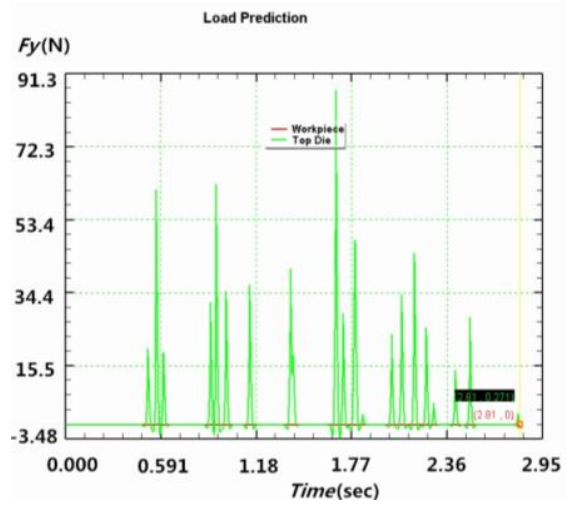

Fig. 2 Normal size of meshing of milling tool and workpiece: a - Dimensional gridding of the work piece; $b$ - Cutting force curve of normal size

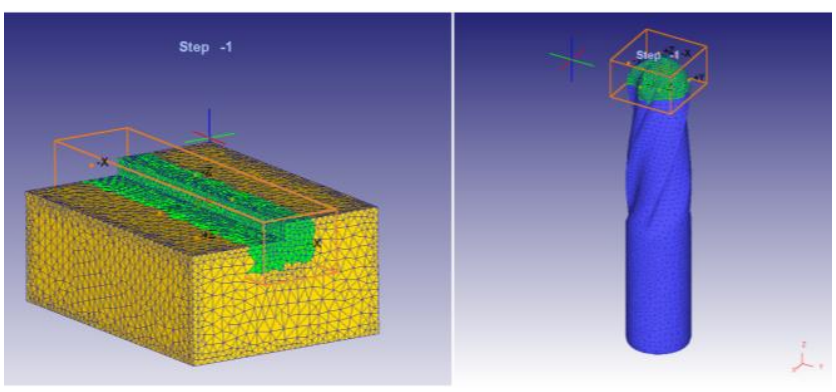

Fig. 3 Model and meshing of milling tool and workpiece

The boundary conditions of milling process were concise; all the surfaces of workpiece were set to a fixed form. Figure 4 shows the detailed settings of motion parameters of cutting tool and boundary conditions in the module of pretreatment. Spindle speed, feed speed and cutting depth as three main influencing factors on cutting parameters and it also restrict dynamic change of milling force in natural marble milling.

\section{Analysis on the results of the simulation and experiment}

\subsection{Experiment arrangement}

The milling equipment in the experiment was the irregularity stone turn-milling machining center (HTM50200). Dry cutting was used in the test. Kistler dynamometer system (as shown in Fig. 5) was used for acquiring and analyzing on milling force of natural marble. The principle of measurement is shown in Fig. 6. The Kistler dynamometer can measure three-component cutting force $F x, F y$ and $F z$.

\subsection{Analysis on the experiment and simulation curve}

In order to verify the accuracy of Deform-3D simulation on cutting force of natural marble, comparative analysis of force curve by practical machining and simulation was carried out. The experiment and simulation were conduct- 
ed under the same machining parameters, which is the same cutting length, $75 \mathrm{~mm}$ and the same cut step distance between two cutting path , 2 mm. Fig. 7 and Fig. 8 illustrate the cutting force curve obtained by experiment and the cutting simulation after smooth dealing respectively. The numerical cutting force obtained from the experiment and simulation was the average cutting force calculated from the steady part of the cutting force curve [10].
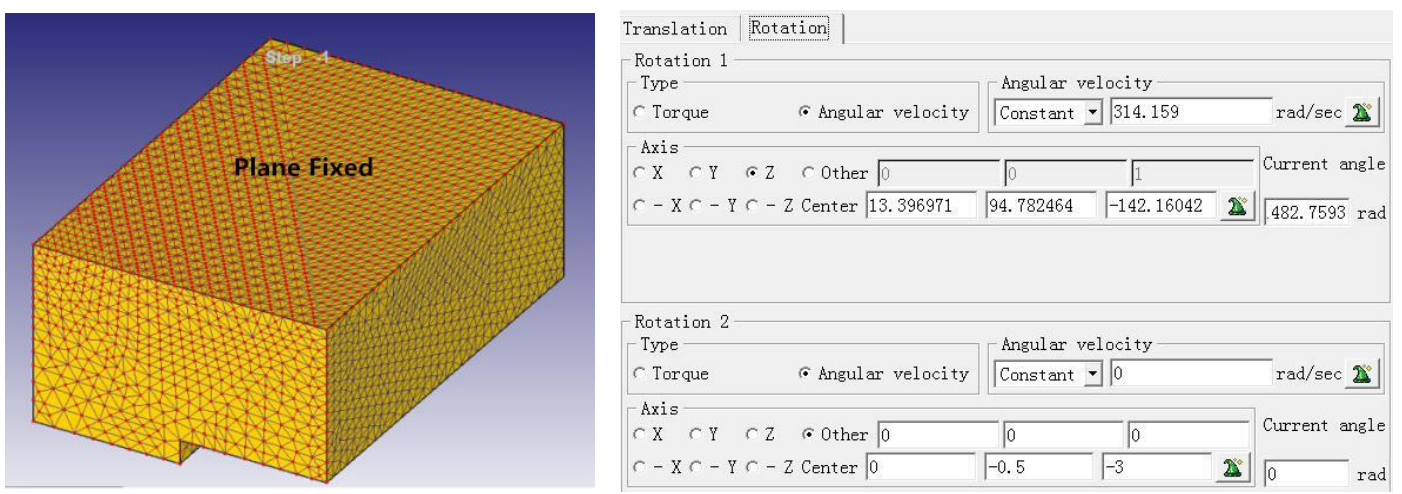

Fig. 4 Motion parameters and boundary conditions: a - Boundary conditions of workpiece; b - Motion parameters of cutting tool

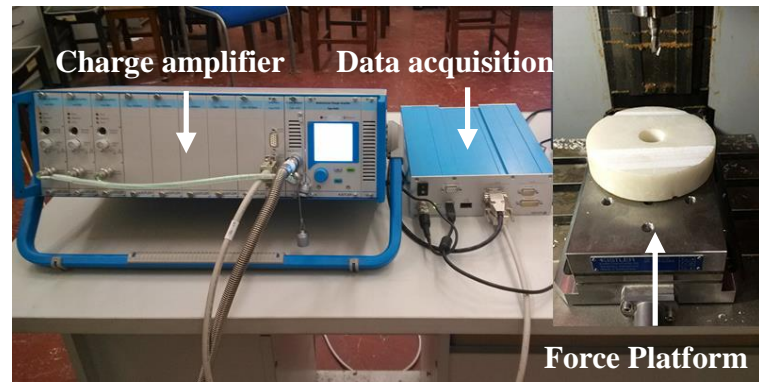

Fig. 5 Kistler dynamometer system

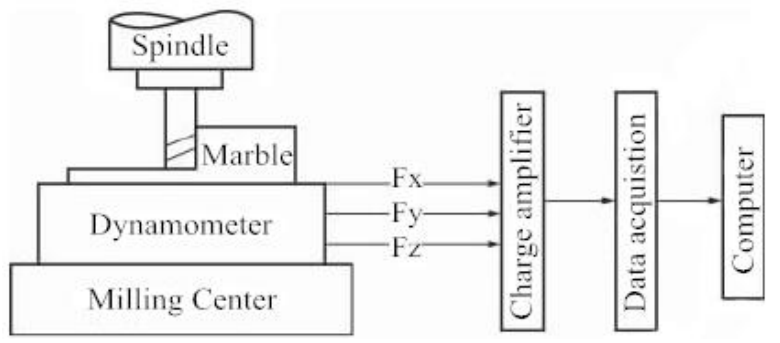

Fig. 6 Measure principle of milling force

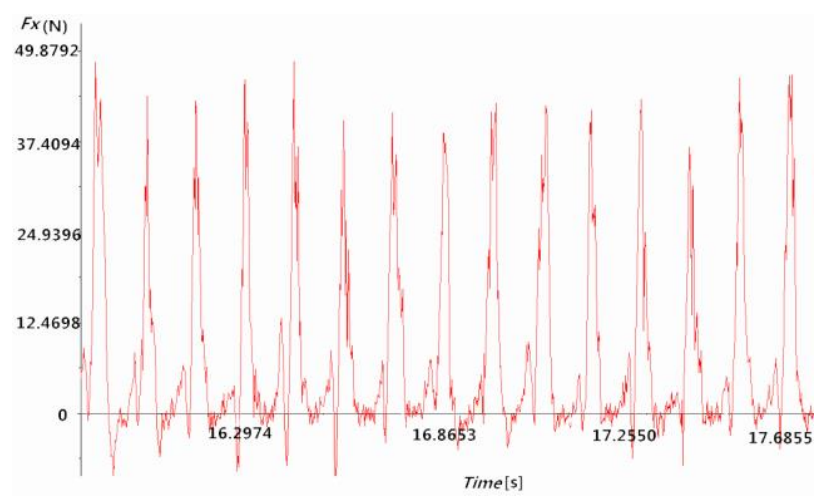

Fig. 7 Cutting force curve of experiment

According to the cutting curve in Fig. 7 and Fig. 8, the cutting force values of coated tools fluctuate within a certain range. The images show the cyclical fluctuations of cutting force between the minimum and maximum values and a gradual decline appears because of the phenomenon of milling blade cut in and out during the machining process. In terms of cutting mechanism, cutting force reaches to the yield limit of the workpiece materials due to the impact and friction [11], the surface material is stripped under the effect of brittle fracture. On one hand, the load on the natural marble is dispersed into many micro fields. Because of the actual contact area is less than theory contact area, each micro-bulge will bear more loads and then abrupt change occurs to cutting force. On the other hand, due to natural marble belongs to hard-brittle materials, most of chips are powder under the joint effect of friction and impact during milling process, the material removal rate is fast, so the change of force is fast-varying. Furthermore, there are a small number of maximum points and catastrophe points in the simulation force curve. This is because that in the pretreatment process, although using grid partition method partly, its main principle still belongs to adaptive partition and some grid division precision is lower, leading to calculation error, during the process of calculating cutting force by Deform-3D. Therefore, in the process of calculating the average force, the extreme point and cutting force catastrophe points should be removed. Orthogonal simulation scheme and results are shown in Table 2.

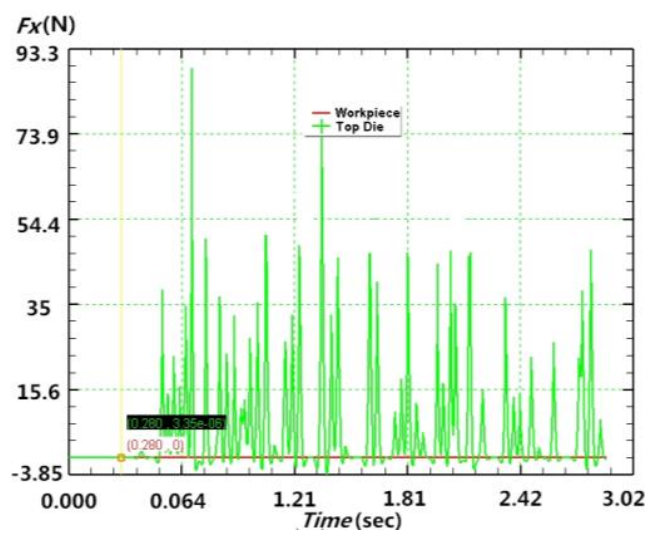

Fig. 8 Cutting force curve of simulation after smoothing

Cutting force values obtained from simulation and experiment are compared in Table 2 . It can be seen that a small number of force values obtained from the experiment and simulation have shown big difference. This is because 
that certain difference exists between actual machining environment and ideal conditions in the simulation and a few errors arise from data transmission. The average error between experimental value and simulation value is within $10 \%$, the overall distribution of simulation tallies with the actual value [12], indicating that the predict method of cutting force of natural marble based on Deform-3D is reliable in terms of the curve shape and the values of the cutting force.

\subsection{Analysis on the effect of parameters on milling force}

In order to study the characteristics of milling force further, the influence mechanism of different cutting parameters on cutting force should be analyzed in this paper. Figure 9 shows the influence curves of cutting parameters on cutting force.

As shown in Fig. 9, the simulative cutting force of natural marble has a tendency to decrease along with the increase of spindle speed, where the Fx and Fy change are obvious. It is because that the cutting speed increases along with the increases of spindle speed. The contact time of cutting edge and workpiece decreases in unit time. Due to the lower thermal conductivity of natural marble, the heat quantity generated from the increased cutting speed can not spill out in time and lead to partly high temperature of natural marble surface and reduces the friction coefficient, softening materials and then reduces the cutting force [13].

In the initial changing stages of spindle speed, the cutting force has an obvious downward trend that indicates the softening effect of material at high temperature is stronger than other factors. When the spindle speed changes from $3000 \mathrm{rmin}^{-1}$ to $5000 \mathrm{rmin}^{-1}$, the downward trend slows down and gradually stays almost unchanged. It is the work hardening phenomenon appears and increases the surface hardness [14] of natural marble. However, its decrease trend is gentle compared with initial change of spindle speed that causes the trend of cutting force changes. The work hardening phenomenon recedes when the spindle speed reaches to 5000-7000 $\mathrm{r} \mathrm{min}^{-1}$.

The curve of cutting force changing with cutting depth is shown in Fig. 10. It can be seen from the curve that cutting force of three directions has an obvious linear increasing trend. The reason of increasing trend of cutting force is that: the cutting area on the axial profile increased with the increase of cutting depth, and the cutting force increased with the cutting volume of cutting blade increased in unit time.

The curvilinear relationship between feed speed and simulate cutting force is shown in Fig. 11.

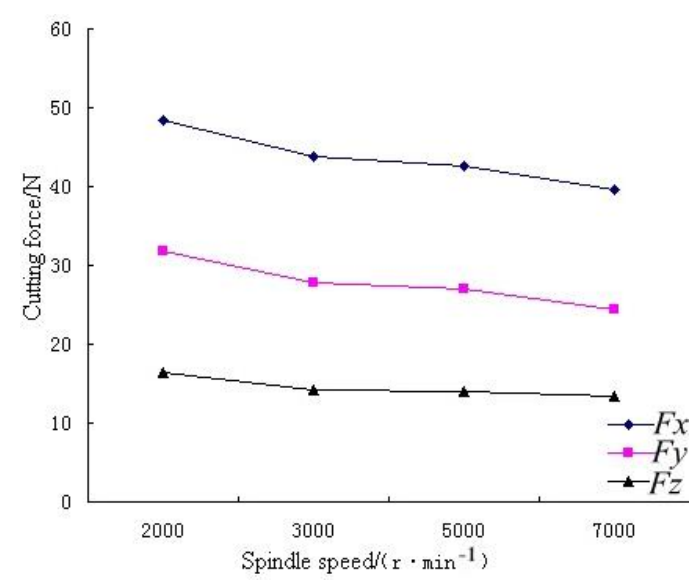

Fig. 9 Curve of spindle speed and cutting force

Table 2

Orthogonal experiment arrangement and results

\begin{tabular}{|c|c|c|c|c|c|c|c|c|c|}
\hline & \multirow{2}{*}{$\begin{array}{l}\text { Spindle } \\
\text { speed, } \\
r \text { min }^{-1}\end{array}$} & \multirow{2}{*}{$\begin{array}{c}\text { Feed } \\
\text { speed, } \\
\text { mm min }^{-1}\end{array}$} & \multirow{2}{*}{$\begin{array}{c}\text { Cutting } \\
\text { depth, } \\
\text { mm }\end{array}$} & \multicolumn{2}{|c|}{$F x, \mathrm{~N}$} & \multicolumn{2}{|c|}{$F y, \mathrm{~N}$} & \multicolumn{2}{|c|}{$F z, \mathrm{~N}$} \\
\hline & & & & $\begin{array}{c}\text { Test } \\
\text { value }\end{array}$ & $\begin{array}{c}\text { Simulate } \\
\text { value }\end{array}$ & $\begin{array}{c}\text { Test } \\
\text { value }\end{array}$ & $\begin{array}{c}\text { Simulate } \\
\text { value }\end{array}$ & $\begin{array}{c}\text { Test } \\
\text { value }\end{array}$ & $\begin{array}{c}\text { Simulate } \\
\text { value }\end{array}$ \\
\hline 1 & 2000 & 1500 & 1.0 & 35.69 & 32.84 & 22.25 & 20.56 & 10.65 & 11.89 \\
\hline 2 & 2000 & 2500 & 2.0 & 45.31 & 40.78 & 31.98 & 29.64 & 12.42 & 13.57 \\
\hline 3 & 2000 & 3000 & 3.0 & 50.32 & 54.81 & 36.62 & 33.51 & 20.21 & 18.69 \\
\hline 4 & 2000 & 3500 & 4.0 & 60.90 & 65.16 & 39.39 & 43.47 & 19.25 & 21.26 \\
\hline 5 & 3000 & 1500 & 2.0 & 38.21 & 35.62 & 23.31 & 20.64 & 12.56 & 11.21 \\
\hline 6 & 3000 & 2500 & 1.0 & 28.63 & 33.35 & 24.20 & 20.44 & 12.32 & 11.05 \\
\hline 7 & 3000 & 3000 & 4.0 & 58.24 & 62.09 & 45.01 & 40.88 & 20.95 & 19.23. \\
\hline 8 & 3000 & 3500 & 3.0 & 48.20 & 43.98 & 32.45 & 29.62 & 14.26 & 15.32 \\
\hline 9 & 5000 & 1500 & 3.0 & 44.74 & 41.44 & 27.32 & 25.99 & 12.80 & 13.50 \\
\hline 10 & 5000 & 2500 & 4.0 & 54.30 & 58.64 & 43.31 & 39.89 & 18.62 & 17.09 \\
\hline 11 & 5000 & 3000 & 1.0 & 36.75 & 33.69 & 22.38 & 20.10 & 14.10 & 12.23 \\
\hline 12 & 5000 & 3500 & 2.0 & 40.21 & 36.96 & 27.57 & 21.96 & 13.90 & 13.21 \\
\hline 13 & 7000 & 1500 & 4.0 & 60.31 & 56.09 & 43.34 & 39.25 & 21.05 & 18.10 \\
\hline 14 & 7000 & 2500 & 3.0 & 47.62 & 43.23 & 32.87 & 28.32 & 16.00 & 15.30 \\
\hline 15 & 7000 & 3000 & 2.0 & 43.64 & 38.26 & 32.65 & 21.80 & 13.32 & 12.69 \\
\hline 16 & 7000 & 3500 & 1.0 & 32.65 & 37.60 & 22.39 & 20.37 & 12.18 & 11.47 \\
\hline \multicolumn{4}{|c|}{ Average error (\%) } & \multicolumn{2}{|l|}{9.1} & \multicolumn{2}{|l|}{9.5} & \multicolumn{2}{|l|}{9.6} \\
\hline
\end{tabular}




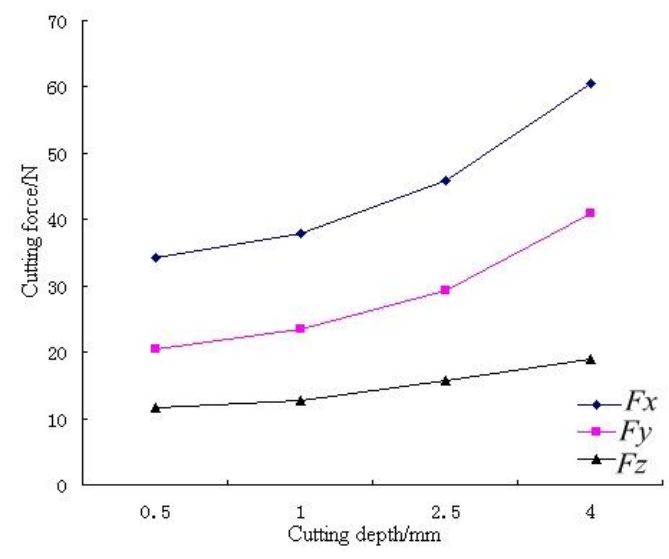

Fig. 10 Curve of cutting depth and cutting force

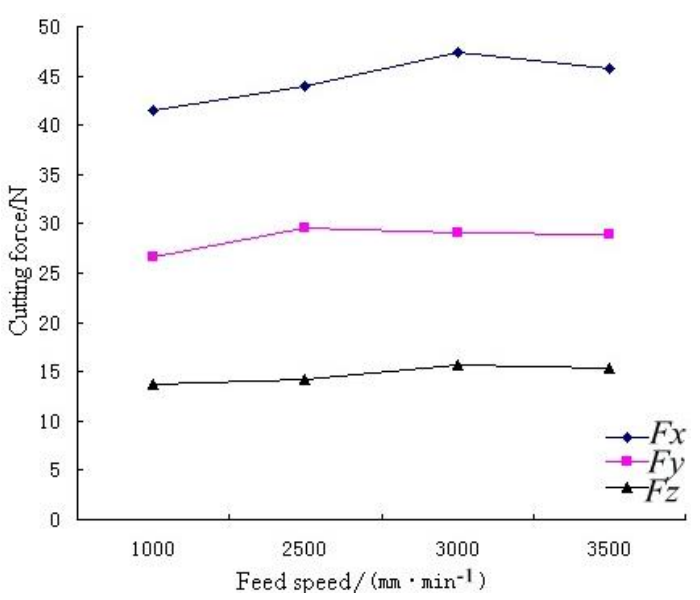

Fig. 11 Curve of feed speed and cutting force

The curve illustrated that cutting force increases along with the increase of feed speed but the range of change is not big and the $\mathrm{X}$ direction cutting force is obvious. The increasing trend is more obvious when the feed speed changes within the range of 1500 to $3000 \mathrm{~mm} \mathrm{~min}^{-1}$. Nevertheless, when the feed speed reaches to the range of 3000 to $3500 \mathrm{~mm} \mathrm{~min}^{-1}$, the brittle-ductile transition appears and cutting force have a gentle decrease trend. Fig. 12 shows the surface texture of natural marble. The plasticity of marble increases with the increases of temperature [15], the Area A of SEM picture has the uneven surface and ravines, which is a typical brittleness removal and the surface of Area B is flat and smooth that indicates ductile cutting occurs on the marble milling process. Part of the surface grain of stone is removed and the rest of the surface has tensile stress, deformation layer of stone has a trend of reinstatement [16] with the effect of plastic extension and the material below the surface has to prevent this kind of change, and then the surface stress has redistribution that leads to decreases of real cutting force.

According to the results of experiment, three parameters restrict the change of milling force. A mathematical formula needs to be figured out using the force data by MATLAB. Eq. (2) shows the mathematic relation between machining parameters and milling force. $X_{1}$ represents spindle speed, $X_{2}$ represents feed speed, $X_{3}$ represents the cutting depth and $Y$ represents the cutting force. The Rsquare statistics is 0.9537 , the $p$ value is 0.0001 and $p<0.05$, indicating the empirical equation is reliable.

$$
\begin{aligned}
Y= & 24.6620 X_{1}-0.0057 X_{1}^{2}+0.0001 X_{2}^{2}+ \\
& +25.7358 X_{3}^{2}-8.6425 X_{3}^{3}+1.2292 .
\end{aligned}
$$

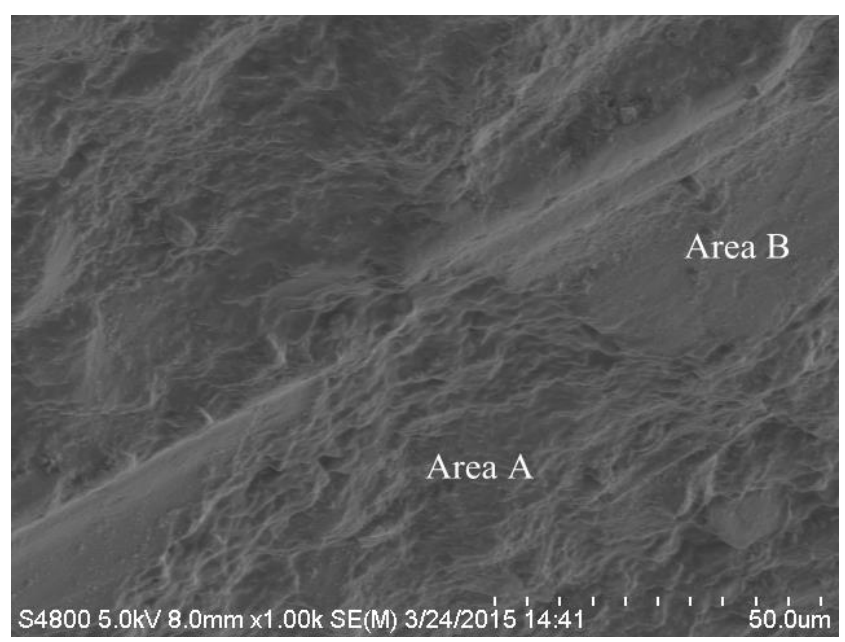

Fig. 12 SEM surface texture of natural marble

\section{Conclusion}

The milling process simulation of natural marble based on Deform-3D was carried out in this paper. The error of cutting force between simulation and experiment is within $10 \%$, suggesting the simulation value is reliable. According to the analysis, the cutting force decreases along with the increase of spindle speed and the downtrend of cutting force slows down due to the work-hardening of workpiece when spindle speed changes around 3000$5000 \mathrm{r} / \mathrm{min}$; the cutting force decreases along with the increase of feed speed. The cutting force has a linear increase due to the axial cutting quantity increases. The cutting force increases as the increase of feed speed below $3000 \mathrm{~mm} / \mathrm{min}$. Once the feed speed reaches to $3000 \mathrm{~mm} / \mathrm{min}$, the brittle-ductile transition appears through the analysis on the SEM picture of natural marble, and then the surface cutting force has a redistribution that decreases the real cutting force. Empirical equation of cutting force was obtained by MATLAB through experimental data. Therefore, large spindle speed and feed speed, small cutting depth can reduce cutting force and the phenomenon of brittle-ductile transition will increase the surface quality and improve cutting performance of coated tool.

\section{Acknowledgement}

This work was financially supported by the Natural Science Foundation of China (51375317), the Ministry of Education Innovation Team Plans (IRT1160); Liaoning Province Natural Science Foundation (2014020069).

\section{References}

1. Wu Yuhou, Zhao Dehong. 2011. Special-shaped stone machining equipment and technology, Vol. 1: 1-7, Beijing, Science Press.

2. Lu Feng, Dehong Zhao, Yuhou Wu. 2011. Modal analysis of special-shaped stone multi-function NC machining menter, International Journal of Digital Content Technology and its Applications 5(8): 168-174.

3. Jalili Saffar, R.; Razfar, M.R.; Zarei, O.; 
Ghassemieh, E. 2008. Simulation of three-dimension cutting force and tool deflection in the end milling operation based on finite element method, Simulation Modelling Practice and Theory 16: 1677-1688. http://dx.doi.org/10.1016/j.simpat.2008.08.010.

4. Xia Liangliang; Yuan Juntang; Wang Zhenhua. 2014. Simulation and experimental study on milling force of aluminum alloy based on Deform-3D, Machinery Design and Manufacture (04): 85-87.

5. Huang Bo. 2006. Research on the efficient processing mechanism of irregularity stone surface, $\mathrm{PhD}$ thesis, Shan Dong University, China, 30-40.

6. Liu Dangsheng. 2009. Metal cutting principle and tools. Beijing, Beijing Institute of Technology press.

7. Joe LuJiAn, Y.S.; Judd, W.R.; Roy, R.F. 1990. Physical properties of rocks and minerals, Beijing, Petroleum Industry Press.

8. Peng Wenwen; Zeng Weidong; Kang Chao. 2011. The development and application of materials database of finite element simulation software Deform, Materials Review B 25(4): 131-134.

9. Matsumura, Takashi; Usui, Eiji. 2010. Simulation of cutting process in peripheral milling by predictive cutting force model based on minimum cutting energy, International Journal of Machine Tools and Manufacture, 467-473.

10. Ren Jialong; Zhang Chunyan; Wang Qing. 2012. Cutting performance of hard processing materials based on the DEFORM-3D, Advanced Materials Research 500: 8-12.

http://dx.doi.org/10.4028/www.scientific.net/AMR.500 8 .

11. Zhang Ping Kuan; Wang Hui Lin; Sun Wang Lu; Qin Duo. 2014. Optimize of the structure of the grinding-driller based on deform-3D, Advanced Materials Research 971-973: 618-623.

12. Liu Weiwei; Zhang Lala; Shan Chenwei. 2009. High speed turning processing simulation based on Deform3D, Modern Manufacturing Engineering 11: 91-95.

13. Kharitonov, V.A, Yamteeva, E.R., Usanov, M.Yu. 2014. Method of calculating the preforming parameters of wires in cable-winding with the use of the deform-3d software, Metallurgist 57: 1067-1072. http://dx.doi.org/10.1007/s11015-014-9846-x.

14. Kao, Yung-Chou; Nguyen, Nhu-Tung; Chen, MauSheng; Su, Shin-Tzong. 2014. A prediction method of cutting force coefficients with helix angle of flat-end cutter and its application in a virtual three-axis milling simulation system, International Journal of Advanced
Manufacturing Technology 77: 1793-1809.

http://dx.doi.org/10.1007/s00170-014-6550-8.

15. Huang Hui; Huang Chongfa; Xu Xipeng. 2008. Force characteristics in drilling of engineering ceramic with a brazed diamond tool, Key Engineering Materials 359-360: 153-157.

http://dx.doi.org/10.4028/www.scientific.net/KEM.359 $-360.153$.

16. Wu Yuhou; Yan Guangyu. 2014. Research on the wear characteristics of CVD composite coated tool in the natural marble cutting, Journal of Shenyang Jianzhu University 30: 712-717.

Yan Guangyu, Wu Yuhou, Zhao Dehong, Wang He

\section{SIMULATION AND EXPERIMENT STUDY ON CUTTING FORCE OF COATED TOOL MILLING NATURAL MARBLE}

S u m m a r y

The simulation of coated tool milling natural marble is constructed based on Deform-3D. The influence mechanism of machining parameters on cutting force is analyzed. The results show that the error between cutting forces of simulation and experiment is within 10\%, suggesting the reliability of the simulation results. According to the study, the cutting force decreases along with the increase of spindle speed while the downtrend of cutting force slows down because of workpiece work-hardening when spindle speed reaches around 3000-5000 r/min; the cutting force linearly increases with the changes of cutting depth due to the increase of axial cutting quantity; the cutting force increases as the increase of feed speed below $3000 \mathrm{~mm} / \mathrm{min}$. Once feed speed reaches to $3000 \mathrm{~mm} / \mathrm{min}$, the brittle-ductile transition appears, resulting in redistribution on the surface which decreases the real cutting force; The empirical equation of cutting force is obtained through experimental data, which indicated that large spindle speed and feed speed, small cutting depth can reduce cutting force; the appearance of brittle-ductile transition will increase the surface quality and thus improve cutting performance of coated tool.

Keywords: simulation, cutting force, natural marble, coated tool.

Received September 15, 2015 Accepted July 04, 2016 